\title{
Validation of the IRI-2012 model with GPS-based ground observation over a low-latitude Singapore station
}

\author{
Sanjay Kumar ${ }^{1 *}$, Eng Leong Tan ${ }^{1}$, Sirajudeen Gulam Razul ${ }^{2}$, Chong Meng Samson See ${ }^{2,3}$ and Devendraa Siingh ${ }^{4}$
}

\begin{abstract}
The ionospheric total electron content (TEC) in the low-latitude Singapore region (geographic latitude $01.37^{\circ} \mathrm{N}$, longitude, $103.67^{\circ} \mathrm{E}$, geomagnetic latitude $8.5^{\circ} \mathrm{S}$ ) for 2010 to 2011 was retrieved using the data from global positioning system (GPS)-based measurements. The observed TEC from GPS is compared with those derived from the latest International Reference lonosphere (IRI)-2012 model with three options, IRI-Nequick (IRI-Neq), IRI-2001, and IRI-01-Corr, for topside electron density. The results showed that the IRI-Neq and IRI-01-Corr models are in good agreement with GPS-TEC values at all times, in all seasons, for the year 2010. For the year 2011, these two models showed agreement at all times with GPS-TEC only for the summer season, and for the period 11:00 to 24:00 UT hours (19:00 to 24:00 LT and 00:00 to 08:00 LT) during the winter and equinox seasons. The IRI-2012 model electron density profile showed agreement with constellation observing system for meteorology, ionosphere, and climate (COSMIC) radio occultation (RO)-based measurements around 250 to $300 \mathrm{~km}$ and was found to be independent of the options for topside density profiles. However, above $300 \mathrm{~km}$, the IRI-2012 model electron density profile does not show agreement with COSMIC measurements. The observations (COSMIC and GPS) and IRI-2012-based data of TEC and electron density profiles were also analyzed during quiet and storm periods. The analysis showed that the IRI model does not represent the impact of storms, while observations show the impact of storms on the low-latitude ionosphere. This suggests that significant improvements in the IRI model are required for estimating behavior during storms, particularly in low-latitude regions.
\end{abstract}

Keywords: GPS; IRI-2012 model; COSMIC; Geomagnetic storm

\section{Background}

The electron density distribution in the low-latitude F-region of the ionosphere is obtained by knowing the combined effect of production by EUV flux, loss exchange between $\mathrm{O}_{2}$ and $\mathrm{N}_{2}$, and transport process by means of $E \times B$ plasma drift. The daytime eastward electric field in the ionosphere combined with the north-south geomagnetic field produces $E \times B$ upward plasma drift and is responsible for initiating the well-known phenomena called the fountain effect at the equator, causing the equatorial ionospheric anomaly (EIA) (Moffett and Hanson 1965; Kumar and Singh 2009). The low-latitude ionosphere is highly dynamic due to several phenomena such as EIA

\footnotetext{
*Correspondence: sanjay.skitvns@gmail.com

'School of EEE, Nanyang Technological University, Singapore 639798, Singapore

Full list of author information is available at the end of the article
}

and scintillation caused by plasma bubbles/spread-F (Abdu 2005). This dynamic nature of low latitude/EIA ionosphere affects navigation and communication to a great extent and also poses a challenge to modeling of the ionosphere.

Dual-frequency global positioning system (GPS) signals are affected by variations in the ionosphere due to the presence of electron density (or total electron content), which in turn affect the navigation/positioning capability of GPS and UHF/HF communication. The total electron content (TEC) is defined as the total number of electrons between the satellite and the receiver in a column of unit cross-sectional area. With the large network of GPS receivers available across the world and its continuous operation, GPS has become an intensive tool for studying ionospheric variability during quiet and disturbed periods (Richmond 1995; Fuller-Rowell et al. 1997; Dasgupta et al. 2007; Mukherjee et al. 2010; Kumar and Singh 2011; 
Kumar et al. 2012). Apart from this, GPS also provides data with better accuracy in time and space and hence is widely used in ground-based ionospheric studies (Rama Rao et al. 2006; Bagiya et al. 2009; Kumar and Singh 2009, 2011; Galav et al. 2011). The TEC in the low-latitude/EIA region is subject to day-to-day variability and is a challenging problem for ionospheric modelers (Huang et al. 1989; Klobuchar 1986). In view of this, several models, such as the International Reference Ionosphere (IRI) (Bilitza 2001; Bilitza and Reinisch 2008), Bent model, semi-empirical low-latitude ionospheric model (SLIM) (Anderson et al. 1987), parameterized, real-time ionospheric specification model (PRISM) (Daniell and Brown 1995), Sheffield University plasmasphere ionosphere model (SUPIM) (Bailey et al. 1997), Nequick (Neq) (Nava et al. 2008), and Utah State University Global Assimilation of Ionospheric Measurements (USU-GAIM) (Scherliess et al. 2006) have been developed. Among the models listed above, IRI is being used widely and is routinely updated by the scientific community committee on space research (COSPAR) and international union of radio science (URSI). The latest available IRI model is IRI-2012. The validation of the IRI model for equatorial and low-latitude regions is important because of its growing applications in various military and civilian areas with broad objectives.

Using ionospheric TEC data from geosynchronous satellite measurements, Ezquer et al. (1998) have validated the IRI-95 model over Tucuman $\left(26.9^{\circ} \mathrm{S}, 294.6^{\circ} \mathrm{E}\right)$ during the year 1982 and found that, in general, the model overestimates TEC during the daily minimum and underestimates it for the rest of the day. Nru et al. (1981) used the IRI model to study the variation in TEC at Waltair, India during 21 cases of geomagnetic storms and reported an increase in TEC values in 17 cases of storms. Chauhan and Singh (2010) studied the diurnal, seasonal, and storm time behavior of GPS-based TEC at the low-latitude Agra (geomagnetic latitude (lat.) $27.17^{\circ} \mathrm{N}$, longitude (long.) $\left.78.89^{\circ} \mathrm{E}\right)$ station and compared the results with the data derived from the IRI-2007 model under different options for the topside electron density, i.e., IRI-Neq, IRI-01-Corr, and IRI-2001. They found close agreement between GPS-TEC data and IRI-Neq and IRI-corr data during all seasons between 06:00 and 18:00 LT (local time), while outside this time sector, IRI2001 data matched well with GPS-TEC data. Thus, there exists a wide variability in the TEC values between GPS-measured data and IRI simulations. This discrepancy has to be resolved using simultaneous measurements at different latitudes and using simulation studies with corrections. Lei et al. (2007) compared the electron density profile from constellation observing system for meteorology, ionosphere, and climate (COSMIC) radio occultation ( $\mathrm{RO}$ ) measurements with those observed by incoherent scatter radar (ISR) at Millstone Hill and Jicamarca for a limited number of overhead passes. These preliminary comparisons show that there is agreement between COSMIC retrieved density profiles and those observed by two ISRs (Millstone Hill and Jicamarca). They have also compared COSMIC retrieved NmF2 (F2 peak density) values and those measured by global distributed ionosondes, and found good agreement. These results indicate that electron density profiles retrieved from COSMIC RO measurements can be used for ionospheric studies.

Therefore, in this study, we have taken ionospheric TEC from GPS-based measurements and electron density profiles from COSMIC RO measurements to validate the most recent available IRI-2012 model for the first time over the Singapore region (geographic lat. $01.37^{\circ} \mathrm{N}$, long. $103.67^{\circ} \mathrm{E}$, geomagnetic lat. $8.5^{\circ} \mathrm{S}$ ). The method of data analysis is presented in Section Methods and the results and discussion in Section Results and Discussion. Section Conclusions concludes the paper.

\section{Methods}

The slant TEC along the line of sight is estimated from GPS data recorded in RINEX format with a time resolution of $30 \mathrm{~s}$, which is easily converted into vertical TEC (VTEC) using the simple relation discussed in Mannucci et al. (1993), Langley et al. (2002), Ramarao et al. (2006), and Kumar and Singh (2011). The latitude and longitudes of ionospheric pierce points (IPPs) are calculated using the data from the RINEX navigation message of the respective satellite (Hofmann-Wellenhof et al. 2001). The GPS data at Singapore in the compact RINEX format is downloaded from the International GNSS Service (IGS) website. A FORTRAN script is used to convert the compact format into normal RINEX format.

In addition to GPS data, we also used the IRI-2012 model to derive the TEC and electron density profile at low-latitude Singapore. IRI models estimate the TEC by integrating the electron density profile from the lower boundary to a specified upper boundary (Bilitza 2001). The IRI model is routinely updated, and the latest available version is the IRI-2012, which is accessible from the IRI homepage at (http://IRI.gsfc.nasa.gov). This model provides three different options for the topside electron density options (Neq, IRI-2001, and IRI-01-Corr) and three options for bottomside thicknesses (Bil-2000, Gul-1987, and ABT-2009), which are the most important parameters controlling TEC and the electron density profile (http://omniweb.gsfc.nasa.gov/vitmo/iri2012_vitmo. html). In this study, all three options for topside density and ATB-2009 for bottomside thickness have been used to compute the TEC as well as the electron density profile, and these results are compared with those estimated from GPS and COSMIC RO measurements.

In order to validate the electron density profile obtained from the IRI model, the electron density profile measured from the COSMIC mission is used. The 
COSMIC mission data is stored at the University Corporation for Atmospheric Research in Boulder, USA, and the data is downloaded from its website (cdaacwww.cosmic.ucar.edu). The presence and intensity of geomagnetic storms is characterized by the hourly Dst index obtained from the website of the world data center for geomagnetism at Kyoto University (http://wdc.kugi. kyoto-u.ac.jp).

\section{Results and discussion}

In order to validate the IRI 2012 model for the Singapore region, we used the diurnal variation monthly mean GPS-TEC data for the year 2010 to 2011. The monthly mean is estimated using TEC data during the international quiet days of each month. Figure 1 shows the contour diagram showing diurnal variation of monthly mean GPS-TEC and IRI 2012 model TEC with three different options for topside electron density $\left(N_{e}\right)$, IRI-Neq, IRI 2001, and IRI-01-Corr over Singapore for the year 2010. This contour diagram shows that TEC is found to be highest during the equinoctial months, which is also shown by the IRI-2012 model results. The IRI-2001 model overestimates, while IRI-Neq and IRI-01-Corr underestimates the GPS-TEC. Figure 2 presents the contour diagram showing diurnal variation of monthly mean GPS-TEC and IRI 2012 model TEC with three different options for topside $N_{e}$, IRI-Neq, IRI 2001, and IRI-01-Corr, over Singapore for the year 2011. The seasonal variation in TEC is similar but higher in magnitude than that found in year 2010. Here, the IRI-2012 model with all three options IRI-Neq, IRI-2001, and IRI-01-Corr underestimates the GPS-TEC. To study the real-time comparison between the observations and IRI-2012 model in more detail, the diurnal variation of seasonal mean of GPS and IRI-model TEC has been carried out for both the years 2010 and 2011, as shown in Figure 3a,b. It is seen from this figure that, in general, IRI-Neq and IRI-01-Corr show good agreement with the GPS-TEC at all times, in all seasons, for the year 2010. The IRI 2001 model does not show any agreement with the GPS observations during the year 2010. Figure 3b shows that the IRI-Neq and IRI-01-Corr models are in agreement with GPS-TEC at all times during the summer season only, while during the winter season and equinox, these two models show agreement with GPS only at nighttime for the year 2011. The IRI-2001 model overestimates the GPS-TEC during all seasons and also does not show agreement. Venkatesh et al. (2011) compared GPS TEC with the IRI-2007 models at two Indian stations, Trivandrum and Waltair, and found that the IRI model underestimated the GPS-TEC during the day and overestimated it during the night at both stations. Shastri et al. (1996) reported that the difference between observation and prediction varied with local time and latitude. Recently, Aggarwal (2011) compared GPSTEC with the output of the IRI-2007 model at Rajkot, a station near the northern anomaly crest region in India, and found that good agreement between observations and the model is obtained only during daytime hours. Kumar
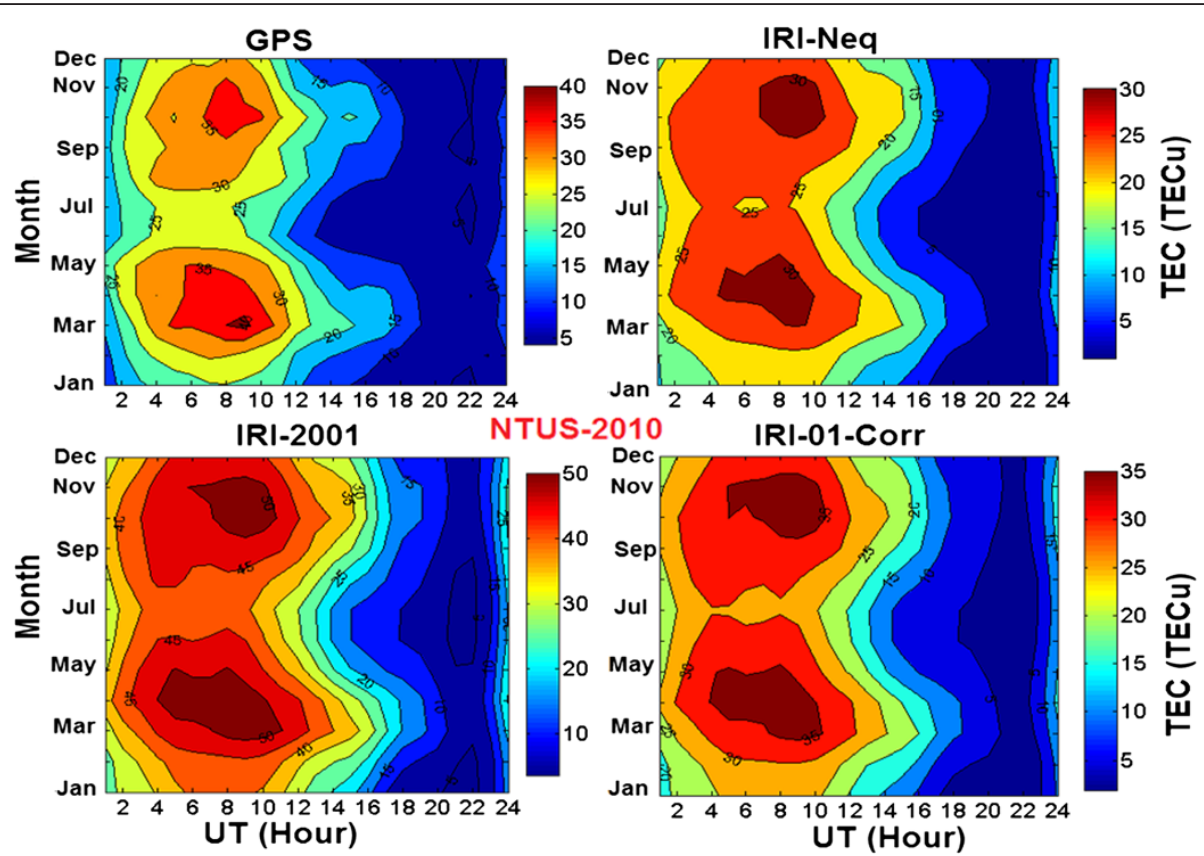

Figure 1 Contour diagram of diurnal variation of monthly mean TEC. Retrieved from GPS and IRI-Neq, IRI-2001, and IRI-01-Corr models over Singapore region for 2010. 

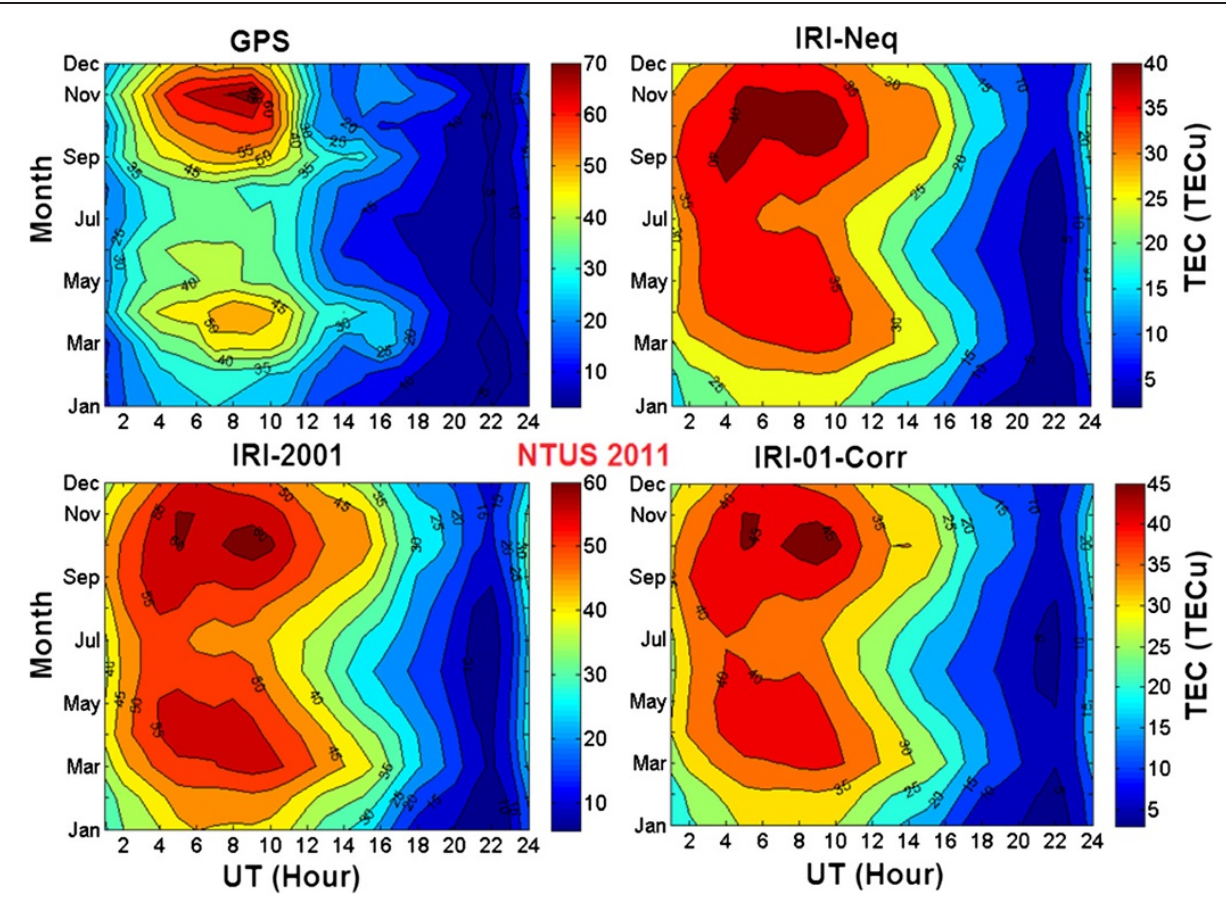

NTUS $2011 \quad$ IRI-01-Corr

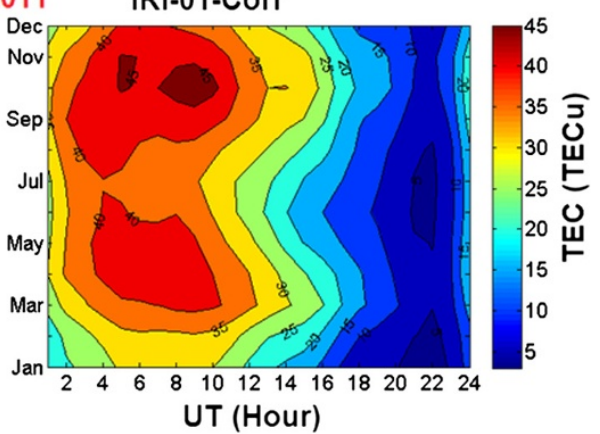

Figure 2 Contour diagram of diurnal variation of monthly mean TEC. Retrieved from GPS and IRI-Neq, IRI-2001, and IRI-01-Corr models over Singapore region for 2011.

et al. (2012) have compared the IRI-2007 model with GPS-TEC at three stations (Varanasi, Hyderabad, and Bangalore) in India during the low solar activity year from 2007 to 2009. Their results showed that at Varanasi and Hyderabad, the IRI-Neq and IRI-01-Corr models are in agreement with GPS-TEC during daytime hours, while at Bangalore, the IRI-2001 model is in agreement with GPS-TEC during daytime hours. In this study, a close agreement between the IRI-2012 model and GPS-TEC has been achieved over the Singapore region during all times for the year 2010, indicating that the IRI-2012 model provides improved results over the IRI-2007 model.

Knowledge on the ionospheric electron density profile is very important from the HF communication point of view, due to its broad military and civilian applications. The electron density profile from experimental probes is not available at every location. Filling this data gap is possible only with a highly accurate model. Therefore, in order to validate the electron density profile estimated from the IRI-2012 model, we have also taken the electron density profile from COSMIC RO measurements. The comparison of the IRI model electron density profile with those from COSMIC RO measurements during each month of the year 2010 over the Singapore region is shown in Figure 4. This figure shows that, in general, the IRI-2012 model electron density profile is in very good agreement with COSMIC RO measurements from 250 - to $300-\mathrm{km}$ altitude over the Singapore region and is independent of the topside option of electron density.
Moreover, for the months of August and October 2010, the IRI model shows very good agreement with COSMIC RO measurements up to $520-\mathrm{km}$ altitude. The electron density profile from all three IRI models, namely IRI-Neq, IRI-2001, and IRI-01-Corr are almost the same from 250- to 350-km altitude, while IRI-2001 and IRI-01-Corr profiles are similar from $400-$ to $600-\mathrm{km}$ altitude. From these results, the IRI-2012 model-based profile is normally found to be in agreement with COSMIC measurements around 250- to 300-km altitudes. Recently, Kakinami et al. (2012) has compared COSMIC-based electron density profiles with those estimated with the IRI-2007 model and showed that the COSMIC-based electron density profile at and above F2 peak altitude is lower than that estimated by the IRI model. For a detailed comparison between the COSMIC and IRI-2012 model profiles, the percentage deviation in the electron density as compared to COSMIC RO measurements at lower $(200 \mathrm{~km})$, peak (hmF2), and topside $(600 \mathrm{~km})$ altitudes has been calculated and are listed in Table 1. The table shows that the difference of electron density at F2 peak altitude $(\triangle \mathrm{NmF} 2)$ estimated from the COSMIC RO and IRI model varies with local time, and their difference is at a minimum $( \pm 3 \%)$ in the afternoon, at approximately14:00 LT (for both cases of 11 August 2010 and 20 October 2010). This difference is also at a minimum at 200 - and $600-\mathrm{km}$ altitudes in the afternoon. However, for other daytime hours, the difference of F2 peak density between the COSMIC RO and IRI model is found to be $\pm 35 \%$ (for both cases of 21 March 2010 and 

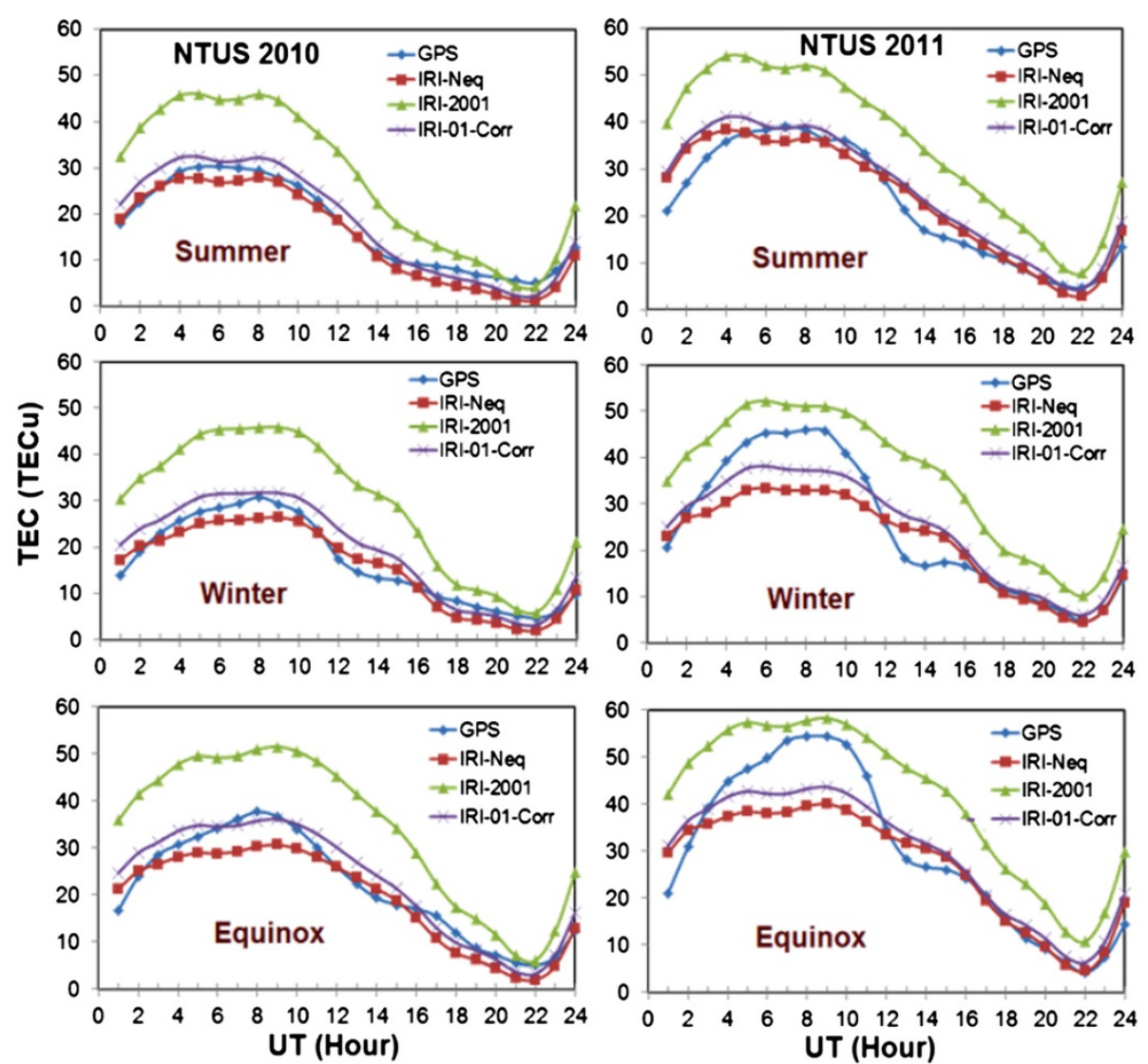

Figure 3 Diurnal variation of seasonal mean TEC. Retrieved from GPS and IRI-Neq, IRI-2001, and IRI-01-Corr models over Singapore region for 2010 and 2011.

10 June 2010). The table also shows that COSMIC RO measurements underestimate the F2 peak density, except during the daytime and afternoon periods. For the case of 20 October 2010 (equinoctial month), the COSMIC RO profile tends to overestimate the $\mathrm{F} 2$ peak density.

The COSMIC RO estimated electron density profiles have significant errors at lower altitudes and topside, mainly at the equatorial and low-latitude belt. It has been reported that the COSMIC RO profiles for the low latitude of EIA regions are significantly influenced by the large electron density of EIA peaks, which results in large errors in measurements of electron densities below 250-km altitudes (Liu et al. 2010). The most probable source for such errors is the hypothesis of spherical symmetry used in the Abel inversion (Tsai et al. 2001; Tsai and Tsai 2004; Liu et al. 2010). Recently, Liu et al. (2010) compared the COSMIC RO-based electron density profile with ground-based digisonde over low-latitude regions and showed that the COSMIC profiles generally underestimate the NmF2 except in the daytime and afternoon and underestimates the hmF2 except in daytime. They further argued that because of the invalidity of the spherical symmetry assumption in the prominent EIA regions, at the geomagnetic equator, the COSMIC RO overestimates $\mathrm{NmF} 2$ in the afternoon, underestimates hmF2 in daytime, and tends to overestimate the electron density below the F2 peak altitude in daytime. In this study, for the case of 20 October 2010 (equinoctial month), the COSMIC RO profile overestimates the F2 peak density at 13:40 LT (afternoon) which is found to be in agreement with those reported by Liu et al. (2010).

The IRI models are used to compute the TEC and electron density profile, and the results are compared with those derived from GPS and COSMIC measurements. To study the impact of geomagnetic storms on the predictability of the IRI model, we have selected a storm that occurred during 24 to 25 October 2011, commencing at around 21:00 UT on 24 October 2011 (LT $=$ UT + 08:00 $=05: 00$ LT on 25 October 2011). The minimum Dst excursion (Dst $\left.{ }_{\text {min }} \sim 132 \mathrm{nT}\right)$ was at around 02:00 UT (10:00 LT) on 25 October 2011 (Figure 5a). The variation of the interplanetary magnetic field (IMF $B_{z}$ ) and interplanetary electric field (IEF $E_{y}$ ) during 24 to 28 October 2011 is shown in Figure 5a,b. The IMF $B_{z}$ turned southward at around 21:00 UT on 24 October 2011 (05:00 LT on 25 October 2011) and remained southward up to 01:00 UT (09:00 LT) 

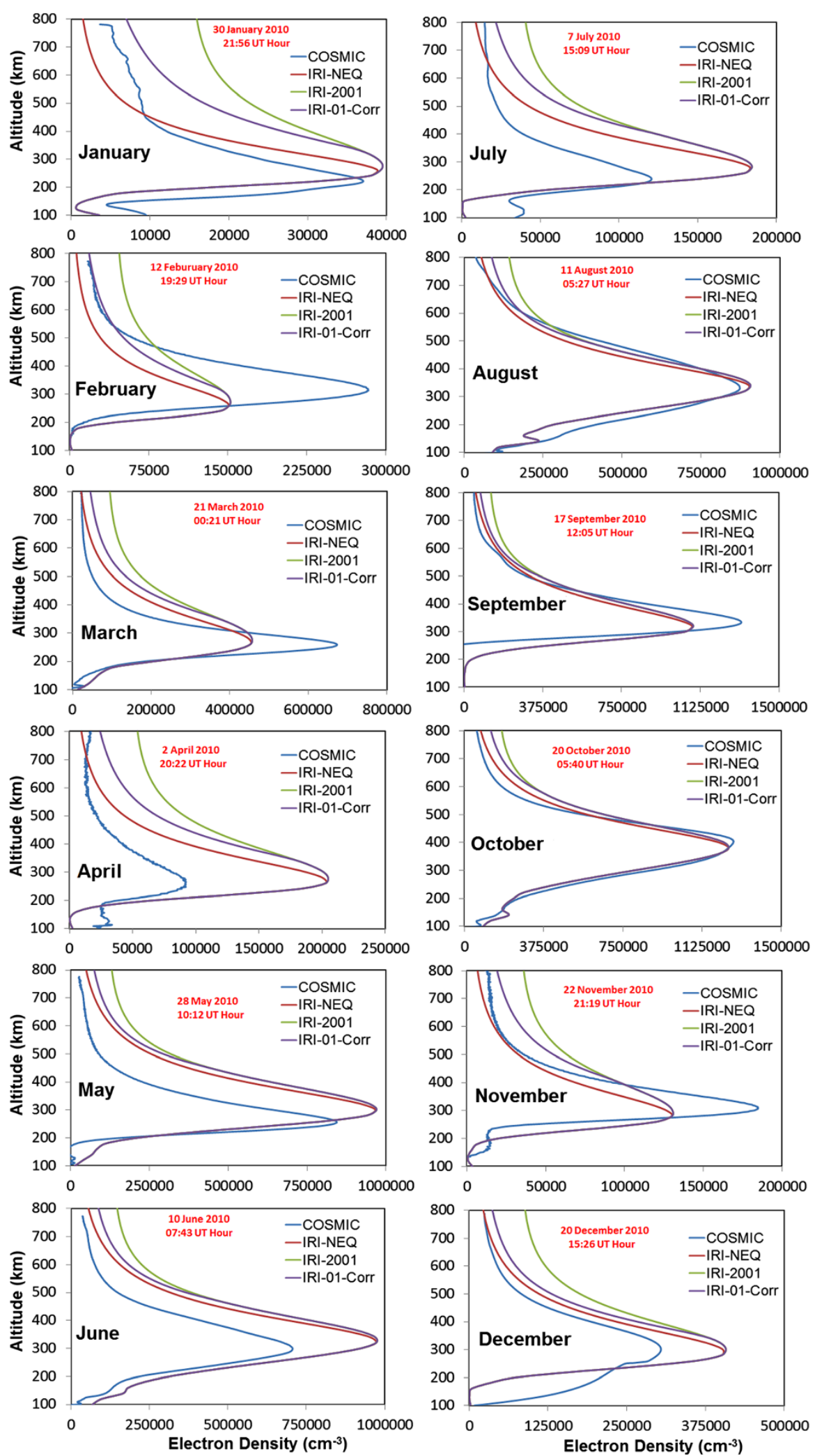

Figure 4 Variation of electron density profile. Retrieved from COSMIC RO and IRI-Neq, IRI-2001, and IRI-01-Corr models over Singapore region for each month of 2010 . 
Table 1 Percentage deviation in electron density estimated by IRI model as compared to COSMIC RO measurements

\begin{tabular}{|c|c|c|c|c|c|c|c|c|c|}
\hline \multirow[t]{2}{*}{ Date (time) } & \multicolumn{3}{|c|}{$\Delta N_{\mathrm{e}}(\%)$ with IRI-Neq } & \multicolumn{3}{|c|}{$\Delta N_{\mathrm{e}}(\%)$ with IRI-2001 } & \multicolumn{3}{|c|}{$\Delta N_{\mathrm{e}}$ (\%) with IRI-01-Corr } \\
\hline & 200 km & F2 peak $(\Delta \mathrm{NmF})$ & 600 km & $200 \mathrm{~km}$ & F2 peak $(\Delta \mathrm{NmF})$ & $600 \mathrm{~km}$ & 200 km & F2 peak $(\Delta \mathrm{NmF} 2)$ & $600 \mathrm{~km}$ \\
\hline 31 Jan 2010 (05:56 LT) & -44.55 & 4.96 & -51.30 & -4.55 & 6.58 & 146.22 & -44.55 & 6.58 & 53.81 \\
\hline 13 Feb 2010 (03:29 LT) & 209.69 & -46.80 & -46.90 & 209.69 & -46.35 & 94.50 & 209.69 & -46.35 & 11.73 \\
\hline 21 Mar 2010 (08:21 LT) & 10.93 & -32.90 & 78.17 & 10.93 & -32.18 & 301.22 & 10.93 & -32.18 & 165.76 \\
\hline 3 Apr 2010 (04:22 LT) & 71.49 & 119.70 & 75.39 & 71.49 & 121.92 & 412.42 & 71.49 & 121.92 & 227.82 \\
\hline 28 May 2010 (18:12 LT) & 21.80 & 14.51 & 140.10 & 21.80 & 14.88 & 255.60 & 21.80 & 14.88 & 180.82 \\
\hline 10 June 2010 (15:43 LT) & 39.10 & 37.60 & 105.50 & 39.10 & 37.60 & 196.87 & 39.10 & 37.60 & 142.13 \\
\hline 7 July 2010 (23:09 LT) & -32.04 & 51.94 & 36.48 & -32.04 & 52.84 & 225.30 & -32.04 & 52.84 & 138.69 \\
\hline 11 Aug 2010 (14:10 LT) & 32.39 & 3.28 & -16.00 & -32.39 & 3.86 & 19.03 & -32.39 & 3.86 & 0.143 \\
\hline 17 Sept 2010 (20:05 LT) & -63.71 & -17.70 & 16.13 & -63.71 & -17.33 & 52.88 & -63.71 & -17.33 & 28.712 \\
\hline 20 Oct 2010 (13:40 LT) & -10.40 & -1.89 & 43.50 & -10.40 & -1.88 & 82.49 & -10.40 & -1.88 & 77.638 \\
\hline 23 Nov 2010 (05:19 LT) & 45.65 & -29.60 & -11.00 & 45.65 & -29.37 & 140.89 & 45.65 & -29.37 & 77.158 \\
\hline 20 Dec 2010 (23:26 LT) & -65.23 & 32.36 & 29.870 & -65.23 & 33.866 & 169.77 & -65.23 & 33.86 & 65.199 \\
\hline
\end{tabular}

on 25 October 2011 (with a minimum value of $-44.9 \mathrm{nT}$ ). During this time interval, the IEF $E_{y}$ value was eastward and changed by $7.90 \mathrm{mV} \mathrm{m}^{-1}$ (from -1.38 to $6.52 \mathrm{mV}$ $\left.\mathrm{m}^{-1}\right)$. After this, IMF $B_{z}$ turned northward at around 01:00 UT (09:00 LT) and remained northward up to 13:00 UT (21:00 LT) on 25 October 2011 (with a maximum value of $21.3 \mathrm{nT}$ ). During this time interval, the IEF $E_{y}$ value was westward and changed by $-16.40 \mathrm{mV} \mathrm{m}^{-1}$ (from 6.67 to $-9.73 \mathrm{mV} \mathrm{m}^{-1}$ ). After 13:00 UT on 25 October 2011, IMF $B_{z}$ and IEF $E_{y}$ fluctuated with very small amplitudes and did not produce any remarkable effects.

To study the impact of the storm on GPS-based observations and the IRI model, we plotted the TEC during 25 October 2011 and the mean estimated during international quiet days of October 2011 as shown in Figure 5c,d.

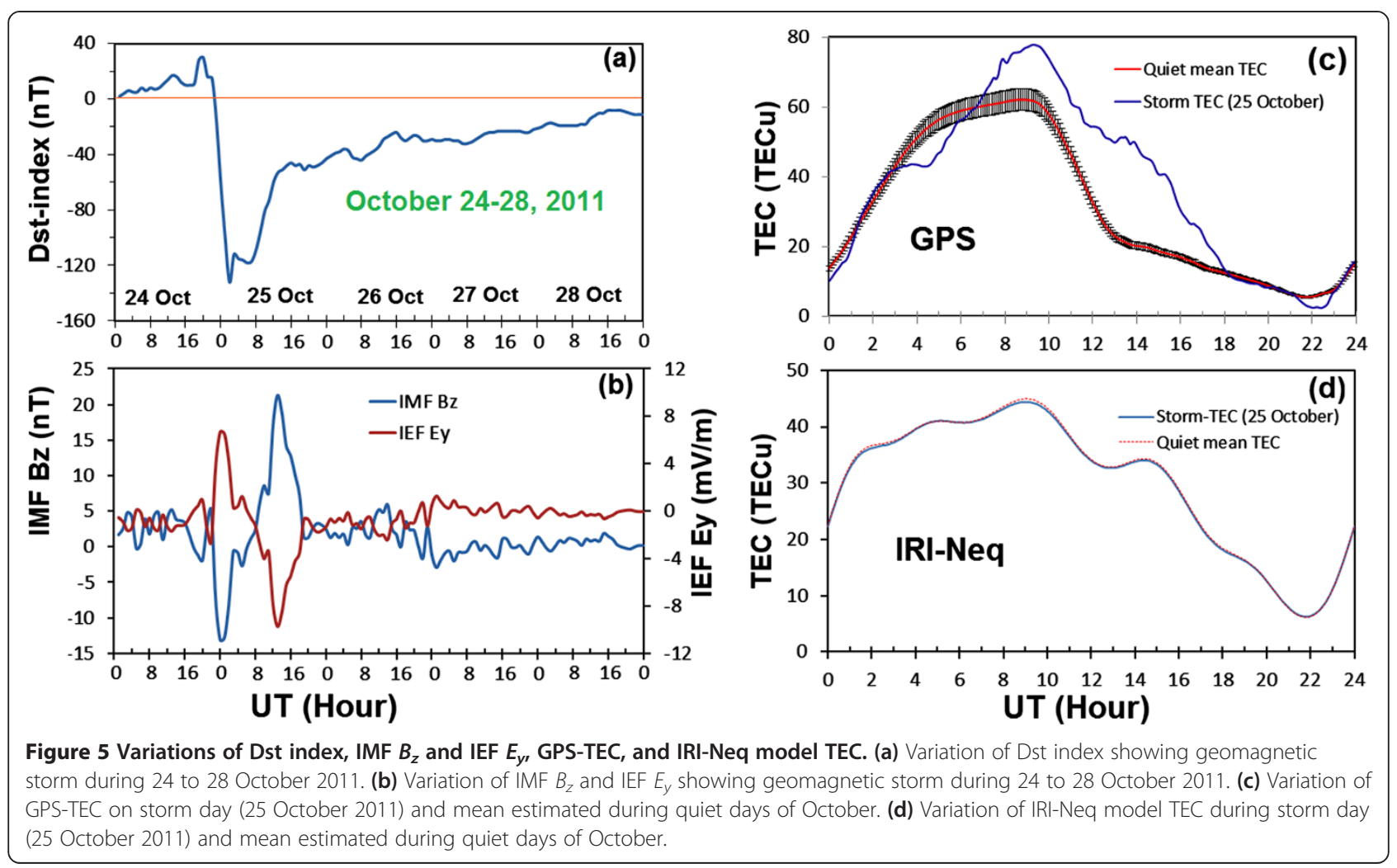


From these, it is seen that GPS-TEC decreased between 03:00 and 04:30 UT and started to increase between 04:30 and 09:30 UT (between 12:30 and 17:30 LT). After 09:30 UT, GPS-TEC started to decrease but was found to be larger compared to the quiet mean TEC between 07:00 and 17:00 UT on the day of the storm (25 October 2011). The maximum enhancement in GPS-TEC on the storm day compared to a quiet day is found to be appoximately 30 TECU at around 13:30 UT (21:30 LT).

Fejer and Scherliess $(1995,1997)$ and Abdu (1997) have shown that the response of the equatorial and lowlatitude ionosphere to geomagnetic storms is strongly dependent on local time. Recently, it has been emphasized again that the prompt penetration of electric fields to the low and equatorial latitudes generally lasts for about an hour (Fejer et al. 2007). In the case of the dawn-to-dusk prompt penetration (PP), the electric field is directed eastward during the day and enhanced the low-latitude $E \times B$ drift of the ionization. The uplifted plasma then diffuses along the magnetic field lines towards higher altitudes where recombination rates are smaller, giving an enhanced value of TEC. For our case, during the period 01:00 to 13:00 UT (09:00 to 21:00 LT) on 25 October 2011, the IEF $E_{y}$ was westward (opposite to the zonal electric field), which leads to downward plasma drift (by $E \times B$ drift mechanism) and hence to plasma loss through the enhanced recombination process at lower altitudes between 03:00 and 04:30 UT on 25 October 2011. Thus, the lower value of TEC compared to the quiet mean value was observed during 03:00 to 04:50 UT (11:00 to 12:50 LT) on 25 October 2011.

The GPS-TEC started to increase between 04:30 and 09:30 UT and remained higher than the quiet mean value between 07:00 and 17:00 UT on 25 October 2011. The IEF $E_{y}$ during this period was westward, so the role of the penetrating electric field during this period was to reduce the TEC. The other possibility of enhancement in TEC is the storm-induced equatorward winds, which may lift the ionospheric layers to higher altitudes (Lin et al. 2005; Kumar and Singh 2011), where the recombination loss becomes smaller. This may result in an enhancement of EIA peak densities. Thus, the equatorward neutral wind in the northern hemisphere produces a larger TEC enhancement than that produced by storm-generated upward $E \times B$ drifts. Such cases, using observation and simulation results, have also been discussed by earlier researchers (Lin et al. 2005; Kumar et al. 2012).

The IRI-model TEC on the storm day is found to be the same as the quiet mean value, indicating that the IRI model is not able to predict the storm's impact. To confirm this, we have also taken the data of ionospheric electron density profiles estimated from COSMIC RO measurements and the IRI-Neq model at around 09:00 UT (17:00 LT) on the storm day, and the mean estimated during the international quiet days at the same time in October 2011, which is shown in Figure 6a,b. COSMIC has very limited passage, and it does not pass every day over the Singapore region, but by chance it passed over Singapore at around 09:00 UT (17:00 LT) on the day of the storm (25 October 2011). The mean of COSMIC data is also estimated at around the same time during the quiet days. From this figure it is seen that the COSMIC electron density on the storm day is found to increase compared to the quiet mean value, up to altitudes greater than $300 \mathrm{~km}$. The height of maximum electron density is also shifted to a higher value approximately $420 \mathrm{~km}$ on the storm day and from approximately $380 \mathrm{~km}$ on the quiet day. The IRI model electron density on the storm day is found to be the same as the quiet mean value at all altitudes (Figure 6b), which is also similar to those predicted by the IRI-TEC results (Figure $5 \mathrm{c}$ ). Using the data from the IRI model, Nru et al. (1981) studied the variations in TEC over the Waltair region during the 21 cases of geomagnetic storms, and they found enhancement in TEC during only for 17 out of the 21 cases. This indicates that the IRI

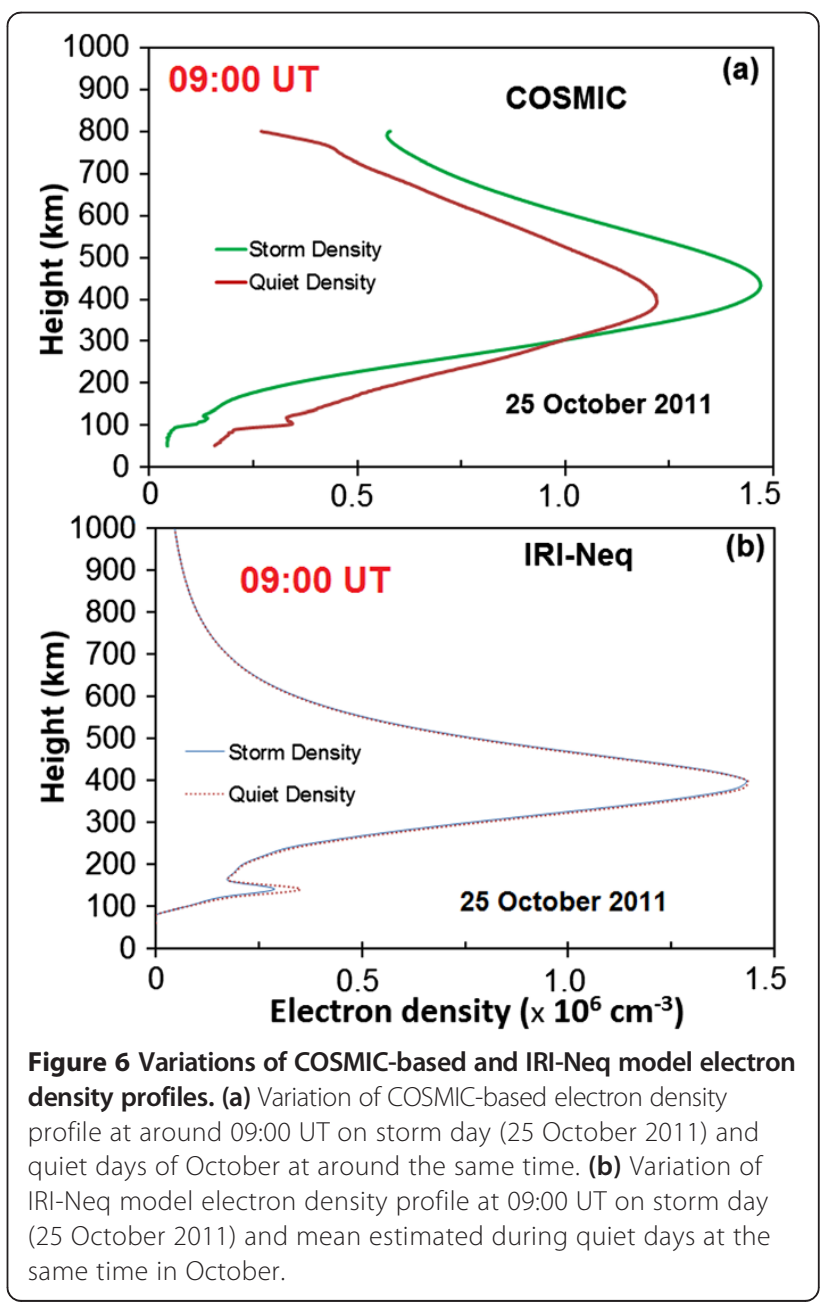


model was not able to predict the storm's impact for 4 cases out of 21 . Using the data from the IRI-2007 model and GPS-based TEC over Malindi ( $\left.2.9^{\circ} \mathrm{S}, 40.1^{\circ} \mathrm{E}\right)$ Kenya, Olwendo et al. (2011) showed that the IRI-2007 model does not respond to geomagnetic storms, while the GPSTEC does. Thus, based on this study, the IRI model does not reproduce the storm effects and there is a need to study more cases of storms to see how more storm-related parameters can be included in the model to reproduce such changes.

\section{Conclusions}

GPS-based TEC over a station in low-latitude Singapore during the year 2010 to 2011 has been compared with those derived from the most recently available IRI-2012 model. The results showed that the IRI-Neq and IRI-01Corr models are in good agreement with the GPS-based measurements for all seasons and all times, while the IRI 2001 model overestimated the GPS-TEC. For the year 2011, these two models show agreement with GPS-TEC during all times only for the summer season, while for the winter season and equinox, these two models showed agreement only from 11:00 to 24:00 UT. The electron density profile retrieved from COSMIC measurements during each month for the year 2010 has been compared with those from the IRI model, and it is found that, in general, the IRI-2012 model density profile shows good agreement for up to 250 to $350 \mathrm{~km}$, independent of the options for topside density profiles (i.e., IRI-Neq, IRI2001, and IRI-01-Corr). Conversely, the IRI model density profile does show good agreement above $350 \mathrm{~km}$.

The ionospheric TEC data estimated from observation (GPS) and the IRI-2012 model has been analyzed during quiet and storm periods, and it is found that the IRI model is not able to predict the storm impact, while observation data predicts it. In order to confirm the storm impact prediction capability of the IRI model, the electron density profile estimated from observation (COSMIC RO) and the IRI model has also been analyzed during quiet and storm periods with the same results as observed from TEC data. This suggests that significant improvements in the IRI model are required for estimating behavior during storms, particularly in low-latitude regions.

\section{Competing interests}

The authors declare that they have no competing interests.

\section{Authors' contributions}

SK developed the main framework of the manuscript, carried out the data analysis and interpretation of results, and drafted the manuscript. SK, ELT, SGR, CMSS, and DS actively participated in the discussion and suggestions during the preparation as well as revision of the manuscript to improve and make it finalize. All authors read and approved the final manuscript.

\section{Acknowledgements}

The authors are thankful to the World Data Center for Geomagnetism at Kyoto University, Japan for providing geomagnetic data and the International GNSS Service (IGS) team for providing GPS data. The authors also wish to thank the anonymous reviewers for their constructive suggestions that helped improve this manuscript.

\section{Author details}

'School of EEE, Nanyang Technological University, Singapore 639798, Singapore. ${ }^{2}$ Temasek Laboratories, Nanyang Technological University, Singapore 637553, Singapore. ${ }^{3}$ DSO National Laboratories, Singapore 118230, Singapore. ${ }^{4}$ Indian Institute of Tropical Meteorology, Dr. Homi Bhabha Road, Pashan, Pune 411008, India.

Received: 2 September 2013 Accepted: 8 December 2013 Published: 22 April 2014

\section{References}

Abdu MA (1997) Major phenomena of the equatorial ionosphere-thermosphere system under disturbed conditions. J Atmos Solar-Terr Phys 59(13):1505-1519

Abdu MA (2005) Equatorial ionosphere thermosphere system: electrodynamics and irregularities. Adv Space Res 35(5):771-787

Aggarwal M (2011) TEC variability near northern EIA crest and comparison with IRI model. Adv Space Res 48:1221-1231

Anderson DN, Mendillo M, Herniter B (1987) A semi-empirical low lattitude ionospheric model. Radio Sci 22(2):292-306

Bagiya MS, Joshi HP, Iyer KN, Aggarwal M, Ravindran S, Pathan BM (2009) TEC variations during low solar activity period (2005-2007) near the equatorial ionospheric anomaly crest region in India. Ann Geophys 27:1047-1057

Bailey GJ, Su YZ, Balan N (1997) The Sheffield University plasma sphere ionosphere model- a review. J Atmos Solar-Terr Phys 59(13):1541-1552

Bilitza D (2001) International Reference lonosphere 2000. Radio Sci 36:261-275

Bilitza D, Reinisch BW (2008) International Reference lonosphere 2007: improvements and new parameters. Adv Space Res 42(4):599-609

Chauhan V, Singh OP (2010) A morphological study of GPS-TEC data at Agra and their comparison with the IRI model. Adv Space Res 46:280-290

Daniell RE, Brown LD (1995) PRISM: a parameterized real-time ionospheric specification model version 1.5. Computational Physics Inc, Newton

Dasgupta A, Paul A, Das A (2007) lonospheric total electron content (TEC) studies with GPS in the equatorial region. Ind J Radio Space Phys 36:278-292

Ezquer RG, Jadur CA, Mosert de Gonzalez M (1998) IRI-95 TEC predictions for the South American peak of the equatorial anomaly. Adv Space Res 22(6):811-814

Fejer BG, Scherliess L (1995) Time dependent response of equatorial ionospheric electric fields during magnetically disturbed conditions. Geophys Res Lett 22:851-854

Fejer BG, Scherliess L (1997) Empirical models of storm-time equatorial zonal electric fields. J Geophys Res 102:24047-24056

Fejer BG, Jensen JW, Kikuchi T, Abdu MA, Chau JL (2007) Equatorial ionospheric electric fields during the November 2004 magnetic storm. J Geophys Res 112:A10304, doi:10.1029/2007JA012376

Fuller-Rowell TJ, Codrescu MV, Fejer BJ, Borer BW, Mar-cos H (1997) Dynamics of the low latitude thermosphere: quiet and disturbed conditions. J Atmos Sol-Terr Phys 59:1533-1540

Galav P, Sharma S, Pandey R (2011) Study of simultaneous penetration of electric fields and variation of total electron content in the day and night sectors during the geomagnetic storm of 23 May 2002. J Geophys Res 116, A12324

Hofmann-Wellenhof B, Lichtenegger H, Collins J (2001) Global positioning system: theory and practice, 5 th edn. Springer, Berlin

Huang YN, Cheng K, Chen SW (1989) On the equatorial anomaly of the ionospheric total electron content near the northern anomaly crest. J Geophys Res 94:13515-13525

Kakinami Y, Liu J-Y, Tsai L-C (2012) A comparison of a model using the FORMOSAT-3/COSMIC data with the IRI model. Earth Planets \& Space 64:545-551

Klobuchar J (1986) Design and characteristics of the GPS ionospheric time delay algorithm for single frequency users. In: Proceedings of PLANS'86 - position location and navigation symposium. Las Vegas, pp 280-286, 4-7 Nov 1986

Kumar S, Singh AK (2009) Variation of ionospheric total electron content in Indian low latitude region of the equatorial anomaly during May 2007-April 2008. Adv Space Res 43:155-1562 
Kumar S, Singh AK (2011) Storm time response of GPS-derived total electron content (TEC) during low solar active period at Indian low latitude station Varanasi. Astrophys Space Sci 331:447-458

Kumar S, Priyadarshi S, Seemala GK, Singh AK (2012) GPS-TEC variations during low solar activity period (2007-2009) at Indian low latitude stations. Astrophys Space Sci 339:165-178

Langley R, Fedrizzi M, Paula E, Santos M, Komjathy A (2002) Mapping the low latitude ionosphere with GPS. GPS World 13(2):41-46

Lei J, Syndergaard S, Burns AG, Solomon SC, Wang W, Zeng Z, Roble RG, Wu Q, Kuo Y-H, Holt JM, Zhang S-R, Hysell DL, Rodrigues FS, Lin CH (2007) Comparison of COSMIC ionospheric measurements with ground-based observations and model predictions: preliminary results. J Geophys Res 112, A07308, doi:10.1029/2006JA012240

Lin CH, Richmond AD, Hellis RA, Bailey GJ, Lu G, Liu JY, Yeh H-C, Su S-Y (2005) Theoretical study of the low- and midlatitude ionospheric electron density enhancement during the October 2003superstorm: relative importance of the neutral wind and the electric field. J Geophys Res 110:A12312, doi:10.1029/2005JA011304

Liu J-Y, Lee C-H, Yang J-Y, Chen C-Y, Reinisch BW (2010) Electron density profiles in the equatorial ionosphere observed by the FORMOSAT-3/COSMIC and a digisonde at Jicamarca. GPS Solut 14:75-81

Mannucci AJ, Wilson BD, Edwards CD (1993) A new method for monitoring the Earth's ionosphere total electron content using the GPS global network. Proceedings of ION GPS-1993, Institute of Navigation, Manassas, pp 1323-1332

Moffett RJ, Hanson WB (1965) Effect of ionization transport on the equatorial F-region. Nature 206:705-706

Mukherjee S, Sarkar S, Purohit PK, Gwal AK (2010) Seasonal variation of total electron content at crest of equatorial anomaly station during low solar activity conditions. Adv Space Res 46(3):291-295

Nava B, Coisson P, Radicella SM (2008) A new version of the NeQuick ionosphere electron density model. J Atmos Sol-Terr Phys 70(15):1856-1862

Nru D, Ramarao PVS, Niranjan K, Sriramarao M (1981) Storm time variation of TEC over Waltair. Ind J Radio Space Phys 10:31-34

Olwendo OJ, Baki P, Cilliers PJ, Mito C, Doherty P (2011) Comparison of GPS TEC measurements with IRI-2007 TEC prediction over the Kenyan region during the descending phase of solar cycle 23. Adv Space Res 49(5):914-921

Rama Rao PVS, Gopi-Krishna S, Niranjan K, Prasad DSWD (2006) Temporal and spatial variation in TEC using simultaneous measurements from the Indian GPS network of receivers during the low solar activity period of 2004-2005. Ann Geophys 24:3279-3292

Richmond AD (1995) Space weather research prompts study of ionosphere and upper 12 atmospheric electrodynamic. Eos Transaction AGU 77:101-101

Scherliess L, Schunk RW, Sojka JJ, Thompson DC, Zhu L (2006) Utah State University Global Assimilation of Ionospheric Measurements Gauss-Markov Kalman filter model of the ionosphere: model description and validation. J Geophys Res 111, A11315

Shastri S, Aggarwal S, Sethi NK (1996) Performance of IRI model prediction of F-region for Indian latitude. Adv Space Res 18(6):41-44

Tsai LC, Tsai WH (2004) Improvement of GPS/MET ionospheric profiling and validation using the Chung-Li ionosonde measurements and the IRI model. Terr Atmos Ocean Sci 15:589-607

Tsai LC, Tsai WH, Schreiner WS, Berkey FT, Liu J-Y (2001) Comparisons of GPS/MET retrieved ionospheric electron density and ground-based ionosonde data. Earth Planets \& Space 53:193-205

Venkatesh K, Ramarao PVS, Saranya PL, Prasad DSWD, Niranjan K (2011) Vertical electron density and topside effective scale height $(H T)$ variations over the Indian equatorial and low latitude stations. Ann Geophys 29:1861-1872

doi:10.1186/1880-5981-66-17

Cite this article as: Kumar et al:: Validation of the IRI-2012 model with GPS-based ground observation over a low-latitude Singapore station. Earth, Planets and Space 2014 66:17. 